\title{
A Review of the Relationship between Management Research and Management Practice in Mainland China
}

\author{
Zhixiang Deng ${ }^{1, a}$ \\ ${ }^{1}$ Institute of Education of Jianghan University, China \\ adzx10009@sina.com,
}

Keywords: management research;management practice;academic appraisal;review

\begin{abstract}
The divorce between management research and management practice has attracted intensive attention. It means that the findings or theories developed in management research are not used effectively in practices. This paper describes the divorce between management research and management practice, analyzes its causes, and presents the solutions to "upholding heaven and standing on earth" research as well as reform and improvement of academic appraisal system.

It is found in related researches that although many scholars undertake and complete various research projects in the field of management, they are seldom granted theoretical research projects directing at practical management issues proposed and funded by enterprises. Some scholars may participate in management consultation projects funded by large enterprises, which, however, seldom involve the field of theoretical research. Meanwhile, few doctoral dissertations funded or entrusted by enterprises to study the practical problems they are faced with cover the field of management research. Besides, under the circumstance that the international trend leans towards empirical researches on management, the management research issues and hypotheses in many doctoral dissertations in mainland China are essentially "common sense" or "hypotheses", which reflects the divorce between management theory and management practice. The relationship between management research and management practice has attracted the attention of many scholars in mainland China.
\end{abstract}

\section{The Phenomenon of Divorce between Management Research and Management Practice}

Based on the scientificity, relevance to practice and applicability of management research, some researchers divide the divorce between management research and management practice into 5 categories 1:

"Irrelevance" divorce refers to the divorce between management research and management practice caused by the weak relevance to practice of the research subject. Management research is fairly normative and scientific; however, it has very weak relevance to practice; as a result, management research and management practice seem to be independent.

"Detachment" divorce means that management findings or theories are too abstract and there is a lack of secondary management theories and management techniques connected to the specific management circumstance (such as a certain field), as a result, the practitioners of management cannot apply the highbrow management theories and the divorce between management theories and management practice therefore comes into being.

"Inapplicability" divorce refers to the divorce between management research and management practice due to improper application of research findings or theories by management practitioners, for example, the application of theories that do not match the specific circumstance at all, or the application of completely Procrustean theories.

"Non-transitivity" divorce means that the research findings and theories of the management researchers fail to be transferred to management practitioners and thus cannot be applied.

\footnotetext{
${ }^{1}$ Peng He, Causes and Countermeasures of the Gap between Management Research and Management Practice [J].Management Review, 2011 (2): 122-128 
"Lag-behind" divorce means that the research findings and theories on management do not have sufficient explanatory power and predictive power, and as a result, the management practitioners are not confident enough to apply such research findings or theories.

\section{Causes of the Divorce between Management Research and Management Practice}

Compared with the summary of the phenomenon of divorce between management research and management practice, it is more meaningful to analyze the causes of such a phenomenon because exploration into the causes will help to find valuable measures for the problem. The causes of the serious divorce between management research and management practice at present can be summarized into the following aspects2:

The characteristics of management theory as a discipline increases the difficulty of its application in practice

First, management science has developed into a discipline and its relevant theories need to be developed and established in a academically rigorous and logic way, which means a certain gap exists naturally between management theory and relevant practice. Second, the object of management theory research is the complex and variable interpersonal relationships in various organizations and a certain management theory can be established only with certain hypothesis of the various environmental elements; however, during the application of such theory, the various environmental elements in the organization are constantly changing and are even indefinable and unidentifiable. Therefore, even if we apply the theory in specific management practice, we can hardly define the cause and effect between the theory and the specific practice result.

The unreasonable academic appraisal system misleads the researchers of management theory

At present, researchers of management theory are mainly researchers in the management department of colleges, and researchers as college teachers are inevitably affected by the professional appraisal system. Since the grade of journals in which a teacher has published his papers and the number of papers the teacher has published are the major indicators of the academic inspection and appraisal system for college teachers, which is commonly adopted in all colleges, and the rewards and promotion system of college teachers are closely related with such inspection and appraisal, as a result, the researchers engaged in management theory research put the most of their efforts on writing academic papers that can be published in high-grade journals instead of on theories that can be applied in management practice. This directs the problem at journals. At present many high-grade journals focus too much on the novelty and rigorousness of research methods and little on the practical value of the theories, which to a certain extent intensifies the divorce between management theory research and management practice.

Researchers of management theory and management practitioners are separated from the objective point of view and they do not cooperate with each other from the subjective point of view.

At all times and in all over the world, theory researchers are not necessarily practitioners of a certain trade. Theory researchers usually take theory research as their career, while practitioners of the trade may not have the capability for theory research, therefore they develop into two groups which are supposed to share out the work and cooperate with each other: academic researchers and trade practitioners. As for management theory, the ideal state is that researchers of management theory shall base on a number of management practices to extract valuable management theories to guide and enlighten management practitioners so that the two could make mutual improvement. However, the actual state is that, from the objective point of view, researchers of management theory and management practitioners have different jobs. From the subjective point of view, researchers of management theory do not explore management practice on their own initiative and their academic research is not aimed to serving management practice; in contrast, the massive management practitioners have high expectations on management theories, however, they have no ways to apply the theories and would finally regard management theories as trumpery. The

\footnotetext{
${ }^{2}$ Min Xiangxiao, Study on the Jungle Dilemma of Management Theories and Their Reconstruction [J], Journal of UESTC (Social Science Edition), 2014 (4): 53-56
} 
problems of researchers or practitioners are certainly not the only cause of the phenomenon, and lack of interaction and exchange between the academic field and the practice field for a long time is also one.

One-dimensional management research methodology is separated from management practice

The academic circle of management in China has introduced not only the discipline framework of management science but also the mainstream research paradigms and research standpoints from the west, and shows a one-dimensional trend. The representative figure of western Marxism Marcuse once wrote a famous book One-Dimensional Man to criticize the western capitalism. The core view of the book is that the advanced industrial society has successfully suppressed the dimension of negativeness, criticism, and transcendence, and makes the society a one-dimensional society and people living in it one-dimensional man. The word "one-dimensional" used by Marcuse can be used similarly to describe the research in management science in present China, and it can be said that the management research in China is increasingly becoming "one-dimensional management research". One-dimensional man will lose freedom and creativity, and no longer think of or pursue a different life from the real life; one-dimensional management research will cause loss of creativity and abundance, and result in judging knowledge with single indicator. Moreover, one-dimensional management research may also mislead or destroy management practice, for example, it may cause loss of employee's benefits, or it may intensify the conflict between employees and the management. The "thirteen suicides" event in Foxconn is more or less the consequence of management with neglect of the dimension of employees. Given all this, in-depth analysis into one-dimensional management research is very necessary.

\section{Solutions to the Divorce between Management Research and Management Practice}

Management science is a novel and comprehensive interdiscipline subject; in essential, it is a subject that focuses on both theory and practice. Innovation in management science is supposed to be not only new theories and new methods, but also successful practice of such theories and methods. Therefore, it is suggested that "upholding heaven and standing on earth" shall be the criteria for management research ${ }^{3}$.

"Upholding heaven" - theoretical research

"Upholding heaven" refers to three points: the first is to have a good knowledge of frontier theories, namely to know well and apply the frontier theories in the international field of management science and to trace and grasp the hot research areas and hot issues; the second is to regulate research methods, namely to apply international standard research methods in the field of management science; the third is to internationalize research findings, namely to publish academic papers and present research findings in major international journals in the field of management science and to strive for a place in the field.

"Standing on earth" - application research

"Standing on earth" refers to two points: the first is to target accurately the issues with universal significance in the management practice in China. Since the opening and reform, management practice in mainland China is very complex and variable. Many issues do not have universal significance. So in research of management science we must grasp the essence of the issues beyond the superficial phenomenon. Only by addressing the deep-seated universal issues with scientific and theoretical significance and improving the theories can we make contributions to the development of scientific theories. The second is to combine the theories of management science and the practical situation in China to solve practical problems. We should target accurately on the problems, combine the theories of management science and the practical situation in China, and carry out in-depth research to provide guidance for management practice and to solve the practical problems in management.

\footnotetext{
${ }^{3}$ Chen Xiaohong, Zhou Yanju, Building a Management Theory System with Chinese Characteristics [J]. Economic Management Journal, 2008 (23/24): 172-176
} 
Besides, some researchers suggest that reforming and improving the academic appraisal system of management research should be taken as an important measure to solve the divorce between management research and management practice.

\section{Conclusion}

The divorce between management research and management practice exists not only in mainland China but also in the US. Yet the problem in China is more characteristic. By understanding the divorce between management research and management practice and finding out the causes, making "upholding heaven and standing on earth" research, establishing an academic group of management science joined by academic researchers (academic school), consultant (practice school), and company executives (practitioners), building a common academic exchange platform, and developing "engaged scholarship" by multiple sides, the problem of the divorce between management research and management practice will hopefully be solved.

\section{Bibliography}

[1] Qu Renjun, Sun Linyan, Ye Qiongwei, "Reflection on Jungle - Inner Logic of Management Theory System" [J], Science \& Technology Progress and Policy, 2011, 28(11): 1-2.

[2] Tan Liwen, "On Constructing Generally Applicable Management Theory" [J], Chinese Journal of Management, 2009, (3): 285-287.

[3] Sun Jiwei, "Deviation of Management Theory from Practice: Discriminant Criteria, Underlying Causes and Solutions" [J], Chinese Journal of Management, 2009(9): 14-17

[4] Zhang Yuli, "Crux of Scientific Circle Being Divorced from Business One: A Rational Discussion" [J], Chinese Journal of Management, 2008(3): 45-48.

[5] Gao Liangmou, Zhang Yuanyuan, "Causes of Management Theory Jungle and Reflection Thereon: Exploration to Unification" [J]. Modernization of Management, 2009(4): 107-111.

[6] Stephen P. Robbins, Management [M], translated by Sun Jianmin. Beijing: China Renmin University Press, 2008: 26-50.

[7] Wu Haiping, "Exploration on Updating and Improving the Knowledge System on Management" [J]. Academic Exchange, 2009(8): 71-73.

[8] Zhang Yingkui, Modern Management [M]. Beijing: China Machine Press, 2007: 14-36.

[9] Lv Li, "Research Methodology of "Chinese Management"' [J] Economic Forum, 2009(15): 14-15. 